\title{
The New Quality of Aviation Unmanned Aerial Vehicles (UAV) Prevent Psychological Stress of Military Drone Operators
}

\author{
Andreas Werner ${ }^{1,4, *}$, Ulrich Kreutzmann², Stephanie Glowka ${ }^{3}$, Cynthia Schinkel $^{3}$ \\ ${ }^{1}$ Aviation Physiological Diagnostic and Research, Branch I 1, Centre of Aerospace Medicine, German Air Force, Königsbrück, Germany \\ ${ }^{2}$ Aviation Physiological Training Centre, Branch I 1, Centre of Aerospace Medicine, German Air Force, Königsbrück, Germany \\ ${ }^{3}$ Psychological Training and Education, Branch I 1, Centre of Aerospace Medicine, German Air Force, Königsbrück, Germany \\ ${ }^{4}$ Charité University Medicine, Department for Physiology, Center of Space Medicine and Extreme Environments, Berlin, Germany
}

Email address:

andreas.werner@charite.de (A. Werner)

${ }^{*}$ Corresponding author

\section{To cite this article:}

Andreas Werner, Ulrich Kreutzmann, Stephanie Glowka, Cynthia Schinkel. The New Quality of Aviation Unmanned Aerial Vehicles (UAV) Prevent Psychological Stress of Military Drone Operators. Clinical Medicine Research. Vol. 9, No. 1, 2020, pp. 25-30. doi: $10.11648 /$ j.cmr.20200901.15

Received: August 29, 2019; Accepted: November 22, 2019; Published: February 18, 2020

\begin{abstract}
Remotely piloted aircraft (RPA; also called drones) constitute a new dimension in aviation. In the past, the military used RPAs extensively in the conflicts in Iraq and Afghanistan. Meanwhile, they are employed worldwide, which illustrates the new way of future complementary military warfare. It is well known that military personnel develops mental health disorders (MHD) during their military services or after deployments, including military pilots or fighting personnel (15.9 per 1,000 person-years). Despite the assumption that operators of drones compared to pilots are not vulnerable to MHD, because they are not physically involved and far away from combat operations and the battlefield, it becomes apparent that there is evidence that they are affected in the same way. During the last years, typical symptoms of PTSD occurred in such individuals and resulted in a severe disturbance of health (25.0 per 1,000 person-years). Currently, to our best knowledge, only in the U.S. Air Force (USAF) RPA operators participate directly in the act of war also using destructive weapons. Especially in this population, increasing and high levels of psychological stress, fatigue, and rates of MH diagnoses were found, without significant difference in the rates of post-traumatic stress disorder, depressive disorders, and anxiety disorders between RPA operators and traditional pilots. The German Air Force has been using drones up to now exclusively for reconnaissance. According to empiric observation, the development of MHD among German RPAs operators was not observed, but it has to be assumed that we will also find these illnesses if we proceed with this technology. Hence, military policymakers and clinicians should be highly sensitive to the fact that RPA operators also have a high probability of developing mental health disorders, particularly when using remotely piloted aircraft as weapons.
\end{abstract}

Keywords: Remotely Piloted Aircraft (RPA), Operators, Armed Forces, Psychological Stress, Mental Health Disorders, Post-Traumatic Stress Disorders (PTSD)

\section{Introduction}

Otto Lilienthal, who is considered to be the first successful aviator in the history of humankind, made his first well-documented flight more than 125 years ago - on 12 May 1891. In 2016, we celebrated the Lilienthal anniversary year125 years of human flight [1]. Since this first flight, aviation has made a quantum leap forward. The dimensions became larger, ranges longer and payloads heavier, velocities faster, and - above all - flying became safer. This enormous development and progress made mainly in the era of acceleration [2] offer an infinite number of opportunities, which may entail both huge advantages and numerous risks. In his days, Lilienthal would surely never have dreamed that someday there would be something like remotely piloted aircraft. In today's aviation, this is the domain of unmanned aerial vehicles - UAV, also known as drones, which are remotely controlled from the ground and can be flown and 
employed by their operators/pilots over long distances. At this point, it is no longer the pilot/co-pilot who is sitting in the cockpit, actively controlling the aircraft. Instead, the UAV is remotely piloted from a ground-based flight control center, mostly located in the home country. The workload of aircrews is high and steadily increasing. When looking at the entire military flying service, their work is not only risky and dangerous, but it involves significant physical and psychological stress. The possible causes can be attributable to the mission, to irregular working hours (day/night operations) or mission-related situations, which may end one's own life or the lives of others [3]. The development of mental health disorders, which may even result in a post-traumatic stress disorder (PTSD), is well known among military personnel after stressful missions [4, 5] and various data are used for statistical recording [6]. Morbidity rates from 7.6\% [7] up to $18 \%$ were recorded [8], and this depends mainly on the method used to diagnose the disorder [9].

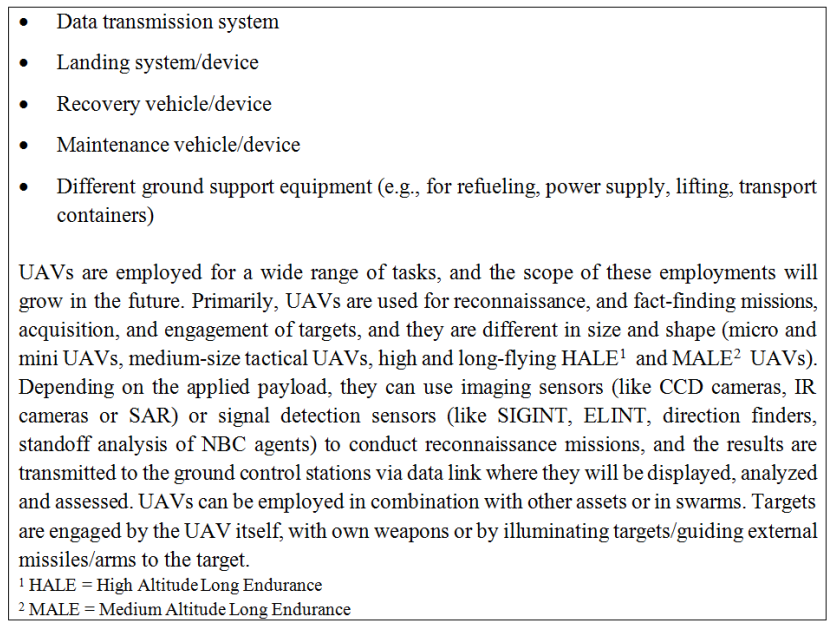

Figure 1. Unmanned Aerial Vehicles (UAV), Definition of the German Aerospace Center [12].

With the new technology, the theater of operations can be monitored precisely, and the modern computer- and satellite-based flight technology allows drone operators to perform military operations around the world from a secure base in their own country, 24 hours a day, seven days a week. These operations, today conducted in real-time, are not always reconnaissance missions but may also include specific engagements in armed conflicts, e.g., in support of ground forces or as independent missions. The question is, whether this new species of aircraft constitutes a sustainable enhancement of existing capabilities [10] or whether the related health risk for the operators is getting out of control. While the physical integrity of the UAV operators is guaranteed, studies show that their mental well-being, however, is severely affected as a result of the new and specific tasks [11]. Both the media and medical experts, in particular in English-speaking countries, have been reporting recently on an increasing number of psychological disorders among UAV operators. However, this is probably a new genesis because this work station constitutes an entirely new dimension of aviation (Figure 1).

\section{Method}

The authors did literature research and combined the findings with their expert knowledge. Used was the literature search engine "pubmed" [46, 13] and other internet-based search machines as well as the own Bibliotheca on base. The results constitute the latest development of the topic.

\section{Result}

\subsection{Unmanned Aerial Vehicles}

By definition, an unmanned aerial vehicle (UAV) is an aircraft that can operate, mostly undiscovered by radar, at high altitudes or fly very low and which is suitable for military or civilian missions [10]. They have become a type of aircraft, which should be considered as critical about their real-time intelligence, surveillance, reconnaissance (ISR) capabilities.

\subsection{Areas of Application}

UAVs can be used for multiple applications: In the civilian sector they are frequently used for infrastructure, border or traffic monitoring or the execution of technical inspections (e.g. of high-voltage transmission towers) [14]; in the military sector, UAVs are primarily used for reconnaissance and fact-finding missions or rescue operations [15], in specific scenarios they will also engage targets (combat drones).

\subsection{Current Employments of Military Drones}

Usually, military drones are equipped with high-resolution, multispectral sensors [15]. Until today, the USA is the only country that develops and produces armed drone systems. It is known that the USA, UK, and Israel have employed combat drones in operational scenarios [16]. In addition to China and Iran, who have self-developed operational combat drones, Russia and Pakistan are in possession of such systems. Turkey has just begun with the development of their own "Anka" drone system. A lot of money is invested in these technologies all over the world. At present, the Bundeswehr has only some reconnaissance drones with relatively short operational range (Table 1) [17]. The MQ-1 Predator and MQ-9 Reaper are the most prominent combat drone systems made in the USA. The Israeli Heron is another top product among the drone systems on the market [17].

The European countries are still dragging behind. Although the efforts for the development of armed UAVs are ongoing, a combat drone that is going to be developed by France, Italy, and Germany is not planned before 2025. In order to close the capability gap in Germany in the meantime, it was decided to authorize the temporary procurement of combat drones (Heron TP, Israel) and the realization of this project was scheduled to start in 2016 [18]. Altogether, this is a response to the global developments, and it became indispensable, 
particularly for NATO and the partners of the alliance [19, 20].

Table 1. Examples of drone systems that are already employed within the scope of military operations - with approximate data on flight endurance and maximum payloads [17].

\begin{tabular}{|c|c|c|c|c|}
\hline Drone System & Manufacturing Country & Flight Endurance (Hours) & Payload (kg) & Mission \\
\hline Aladin / Aladin Twin & Germany & $1-2$ & 0.2 & Reconnaissance (Recce) \\
\hline $\mathrm{KZO}$ & Germany & 3.5 & 35 & Recce / Target Acquisition \\
\hline Luna / Luna NG & Germany & $4-12$ & 13 & Reconnaissance \\
\hline MQ-5B Hunter & USA & $>11$ & 90 & Recce / Combat \\
\hline Patroller & France & 30 & 250 & Reconnaissance \\
\hline Global Hawk & USA & $>35$ & $900-1300$ & Reconnaissance \\
\hline MQ-1 Predator / MQ-1c Gray Eagle & USA & $>30$ & $200-488$ & Recce / Combat \\
\hline MQ-9 Reaper & USA & $>24$ & 1700 & Recce / Combat \\
\hline Heron 1 & Israel & $>40$ & 250 & Reconnaissance \\
\hline
\end{tabular}

\subsection{Requirements to Be Fulfilled by the Operators}

UAVs are remotely piloted by operators in ground-based control centers (remotely piloted aircraft, RPA). Usually, a crew of at least two persons is required to perform the tasks like mission planning, controlling, and operating one single UAV [21]. The operators are primarily concerned with monitoring automated systems [22]. They are provided very detailed information on the terrain overflown, which is gathered by high-end radar systems [10].

\subsection{Drone Pilots in the USA}

At present, as many as 1000 drone pilots are registered in the USA under the designation " $18 X$ " [23]. This is a special unit whose members have to attend a 17-week OSU training course (One Station Unit-Training). This is a combination of basic training and individual follow-on training [23, 24]. Approximately 180 new pilots complete this training every year, but because of the current manpower shortages, they are exposed to permanent stress. This can probably be explained to some extent by the fact that many operators quit their jobs (up to 240 per year), and this outnumbers the recruitments by one third.

The result is a pressing shortage of personnel, which in turn limits the operational capabilities while the total duty hours of individual drone operators are increased considerably [25]. While traditional Air Force pilots fly approximately 300 hours per year, drone operators sit at their terminals 6 to 7 times per week and as long as 12-14 hours per day, spending most of their time in an isolated work environment [26]. These facts support the hypothesis that drone pilots have to master similar or even more demanding psychological challenges than their fellow soldiers in "real" battle situations [27].

\subsection{Drone Pilots in Germany}

In Germany, drone operators of MALE class UAVs are currently recruited among the pilots who are already serving in the Air Force. Originally, flying and controlling a manned aircraft was the main attribute that made the pilot's job attractive. It remains to be seen how these recruitments among the flying personnel for the comparatively repetitive work of a
UAV operator influences their motivation.

\subsection{Criteria to Be Fulfilled by Drone Pilots}

Generally, operators are expected to show a high degree of attentiveness and resilience while being highly tolerant of frustration and resistant against monotony. In contrast to the criteria for pilots of manned aircraft, the primary requirements in this context are not physical fitness or personality traits like sensation-seeking [28], self-assertion, and leadership capabilities. Nevertheless, the requirements for future drone pilots should be very high in specified areas, in order to reduce the aforementioned adverse effects from the outset. This will have considerable consequences for the personnel selection process.

Wickens explains that a UAV operator must be able to quickly access his or her mental processing resources to perform the required tasks accurately and correctly. He must be able to sense and understand the overall situation correctly, plan the mission sequence, and make situation-specific decisions [29].

\subsection{Psychological Stress}

Even though these remotely piloted systems guarantee the physical well-being of the operators, they are working under enormous mental stress $[15,30]$. Within the scope of their tasks, they control flight paths, assess risks, and employ weapons selectively [30]. Hence, the pilots of the United States Air Force (USAF) routinely track enemy targets for some time, aim at the target and finally destroy it [15].

These long-lasting, cognitive demands may involve consequences like higher work loading [31], stress, and diminished situational awareness $[15,32,33]$. The results of the only available semi-experimental study by Lowe and Gire [34] showed that participants who simulated a drone attack and viewed the post-drone attack video reported significantly higher distress than those who viewed only the post-drone attack video. Since not much research has been conducted on this topic, the authors of the study underscore that additional experiments using trained UAV pilots are needed to "establish the ecological validity of the results" [27]. 


\subsection{Possible Psychological Disorders}

In addition, this could lead to a growing number of psychological disorders caused by specific job-related requirements [35]. In this context, the New York Times reported on $22 \mathrm{Feb} 2013$ that UAV pilots experience posttraumatic stress disorder rates similar to those found among pilots of traditional combat aircraft [6].

Strictly speaking, drone pilots do not directly experience a trauma which can be defined in accordance with the diagnosis system: Diagnostic and Statistical Manual V (DSM-V) [27]. However, symptoms like changes in cognition, affect, and behavior that overlaps with PTSD symptoms are frequently found among USAF drone operators [27]. Operators are able to see or imagine the lethal consequences of their actions [36]. As their behavior is often in conflict with their individual moral standards [37], a secondary trauma may follow. Just like in the course of engagements with traditional combat aircraft, UAV engagements may also result in the killing of non-combatants (collateral damage). The dissonance between belief structure and behavior may be even greater when the individuals concerned are unable to handle this moral pressure adequately. They return home to their families keeping the pictures of the devastation they have caused in their minds while, due to the location and isolated nature of their work environment, they do not have the opportunity to share their experiences with like-minded persons (in the form of a de-briefing, stress management among comrades, etc.). This is where US drone operators reach their limits and where they need professional help, which should be provided in the form of an innovative, specific therapy concept following a primarily preventive approach. Because this kind of psychological distress is not, strictly speaking, PTSD [38, 39].

So far, the German Air Force drones are employed for reconnaissance only. Consequently, the daily work routine of a German drone operator differs significantly from the routine of a US operator and is rather characterized by factors like monotony and an isolated work environment. Nevertheless, these working conditions may also involve negative stress, which leads to the associated health problems. A possible conclusion could be mental fatigue, a phenomenon caused by a stability impairment of a person's ability to regulate activities [40].

\subsection{Literature Results}

The number of existing studies show, that there is only little empirical research in this field [41], the findings of the study made in cooperation with Chapelle may be considered indicative for an increased risk of emotional distress among drone operators. IAW the study:

1. $14-26 \%$ of the USAF operators reported high levels of mental fatigue, and

2. $7-17 \%$ of the USAF operators reported high levels of cynicism $[11,34,42]$.

The first study on the self-assessment of drone operators regarding PTSD symptoms was conducted in 2012. The findings indicated that $5 \%$ of the drone operators $(n=670)$ experienced a high risk for PTSD [41]. Most of the affected individuals reported feeling distant or cut off from others, which in turn led to a loss of interest in activities previously enjoyed. Additional symptoms commonly endorsed were:

1. Having difficulty concentrating,

2. Trouble falling and staying asleep, and

3. Feeling upset when something reminded them of a stressful military experience [15].

The latter was confirmed by more than $65 \%$ of the drone operators. According to Otto and Webber, however, many of the affected individuals do not disclose their mental problems at all, because they fear losing their qualification and thus their jobs [43]. Hence, transferring the results of the US studies to the Bundeswehr is doubtful for a number of reasons - for example, different working conditions and various types of employment. It is, therefore, necessary to conduct their own empirical studies to evaluate the stress situation among Bundeswehr UAV operators.

\section{Discussion}

The question is: what's about the future of the Drone Pilots? This is an important question and Germany too has to deal with it as soon as possible, because after the procurement of combat drones has been authorized it seems possible that they will, in fact, be employed. The role of drones is becoming more and more important in the military and in the civilian sector and obviously will not lose its relevance in the future. In view of the emerging problems, general strategies should be developed to prevent negative psychological stress in this work environment and be able to treat or reduce the severity of the psychological injuries that commonly follow combat [27].

It seems recommendable to shape the selection process for potential drone operators and establish specific requirements which must be fulfilled by the drone operator - similar to the personnel in the military flying service - in order to qualify for a career as a drone operator. A high level of mental resilience is of great advantage in this context, since it has a positive effect on the decision-making and acting competence [44]. It has become apparent that the highly cohesive team environment of military Special Forces has a stabilizing effect. The more social support is rendered to the operator by peers, friends, and family, the smaller is his or her vulnerability to combat stress [27].

Training is the most important part of the preparation. In addition to the basic training, mental and aero physiological training should be provided regularly, to ensure that individuals can successfully cope with the demands of their missions permanently [45]. Many of these ideas are already being used for the development of selection and service concepts whose further development is essential with regard to the possible future mission scenarios for unmanned systems.

\section{Conclusion}

The military's interest in drones results from their aim to 
minimize their own injury or mortality risk and above all to avoid their own casualties wherever possible. The cost-benefit aspect is another key factor for the constantly growing spectrum of civilian and military tasks that are assigned to these unmanned aerial vehicles. These new types of military assets will result in lasting changes in military affairs, and this will have far-reaching consequences. There is still a strong demand for mental and physical training of operators. Until today, the high failure rated among US drone personnel cannot be attributed to a specific cause, while chronic work overload could be one reason in accordance with proposed hypotheses [41]. However, the conclusions drawn from previous studies clearly show that drone pilots need to be prepared for the things they are going to see on their screens instead of simply leaving them to their fate [46].

In the past, modern warfare has always caused various types of deployment-related mental traumas including PTSD. Therefore, it seems obvious that this completely new type of warfare will have similar negative effects on the victims. Against this background, it is even more important to establish an effective system of optimized selection, target-oriented training, and preventive mental stabilization measures, in order to prepare future UAV pilots for their job as good as possible.

\section{References}

[1] Otto Lilienthal Museum. Internet: www.lilienthalmuseum.de/olma/news.htm.

[2] Marche S. Is Facebook Making Us Lonely? The Atlantic 2012; 309, 60-69.

[3] Miller G. Drone wars. Science 2012; 336: 842-843.

[4] Pickett T, Rothman D, Crawford EF et al. Mental Health Among Military Personnel and Veterans. N C Med J 2015; 76: 299-306.

[5] Trautmann S, Goodwin L, Höfler M, Jacobi F, Strehle J, Zimmermann P, Wittchen HU. Prevalence and severity of mental disorders in military personnel: a standardised comparison with civilians. Epidemiol Psychiatr Sci 2017; 26: 199-208.

[6] Dao J. Drone Pilots Are Found to Get Stress Disorders Much as Those in Combat Do. The New York Times Feb 22, 2013.

[7] Smith TC, Ryan MA, Wingard DL et al. New onset and persistent symptoms of post-traumatic stress disorder self reported after deployment and combat exposures: prospective population based US military cohort study. BMJ 2008; 336: 366-371.

[8] Litz BT, Schlenger WE. PTSD in service members and new veterans of the Iraq and Afghanistan wars: A bibliography and critique. PTSD Research Quarterly 2009; 20: 1-8.

[9] Coughlin SS. Post-Traumatic Stress Disorder and Other Psychiatric Conditions. In: American Public Health Association. Post-Traumatic Stress Disorder and Chronic Health Conditions. 2013.

[10] Weller W. Der rasante Höhenflug der Drohnen. 2014. Internet: http://edoc.hu-berlin.de/oa/reports/ re3KB1r4OHPYU/PDF/22nlJeOBTJFFo.pdf.

[11] Chappelle WL, McDonald KD, Prince L et al. Symptoms of psychological distress and post-traumatic stress disorder in United States Air Force „drone“ operators. Mil Med 2014; 179 (8 Suppl): 63-70.

[12] Deutsche Gesellschaft für Luft- und Raumfahrt. L3.1 Unmanned Aerial Vehicles (UAV). Internet: www. dglr.de/index.php?id=2502.

[13] https://www.ncbi.nlm.nih.gov/pubmed/.

[14] Petermann T, Grünewald R. Stand und Perspektiven der militärischen Nutzung unbemannter Systeme. 2015. Internet: www.tab-beim-bundestag.de/de/ pdf/publikationen/berichte/TAB-Arbeitsbericht- ab144.pdf.

[15] Chappelle WL, Goodman T, Reardon L, Thompson W. An analysis of post-traumatic stress symptoms in United States Air Force drone operators. J Anxiety Disord 2014; 28: 480487.

[16] Kaleck W. Ausweitung der Kampfzone. Internet: www.imi-online.de/download/doku2013_kaleck.pdf.

[17] Alwardt C, Brzoska M, Ehrhart $\mathrm{HG}$ et al. Braucht Deutschland Kampfdrohnen? 2013. Internet: https://ifsh.de/pdf/publikationen/hifs/HI_50_ Kampfdrohnen.pdf.

[18] Frankfurter Rundschau. Bundeswehr kauft Kampfdrohnen aus Israel. $12 . \quad$ Januar $2016 . \quad$ Internet: http://www.fr-online.de/politik/drohnen-bundes w e hr-k auf t-k am pf drohnen - aus -israel1472596,33505104.html.

[19] Podsiadło P, Bargiel B, Moskal W. Mountain Rescue Operations Facilitated with Drone Usage. High Alt Med Biol 2019; doi: 10.1089/ham.2018.0149. [Epub ahead of print].

[20] Robakowska M, Ślęzak D, Tyrańska-Fobke A, Nowak J, Robakowski P, Żuratyński P, Ładny J, Nadolny K. Operational and Financial Considerations of Using Drones for Medical Support of Mass Events in Poland. Disaster Med Public Health Prep 2018: 1-6. doi: 10.1017/dmp.2018.106 [Epub ahead of print].

[21] Schulte A. Kognitive und kooperative Automation zur Führung unbemannter Luftfahrzeuge. 2013. Internet: http://duepublico.uni-duisburg-essen.de/ servlets/DerivateServlet/Derivate-33216/105_ Schulte.pdf.

[22] Sheridan TB. Telerobotics, Automation and Human Supervisory Control. Computer Science, artificial intelligence. 2003, Cambridge: MIT Press, ISBN 9780262515474.

[23] Powers R. Army Enlisted Job Descriptions and Qualification Factors. 2015. Im Internet: http://usmilitary. about.com/od/enlistedjobs/a/18x.htm.

[24] Ledford H. US drone research hits regulatory turbulence. Nature 2014; 512: 239-240.

[25] Chatterjee P. Desertieren die Piloten, die Washingtons Drohnen-Krieg führen müssen? 2015. Internet: www.ag-friedensforschung.de/themen/Droh nen1/luftpost.html.

[26] Host SS. The Drone War's Bottleneck: Too Many Targets, Not Enough Pilots. 2015. Internet: www.npr. or g/ $\mathrm{t} \mathrm{em} \mathrm{pla} \mathrm{t} \mathrm{e} \mathrm{s/} \mathrm{tr}$ anscr ip $\mathrm{t} / \mathrm{t} \mathrm{r}$ anscr ip $\mathrm{t}$. php?storyId $=379550383$. 
[27] Matthews MD. Special: Stress bei Drohnenpiloten posttraumatische Belastungsstörungen, Existenzkrise oder moralische Verletzung? Ethik und Militär 2014/1: 59-64.

[28] Zuckerman, M. Behavior and Biology: Research on Sensation Seeking and Reactions to the Media. In: Donohew L, Sypher HE, Higgins ET, eds. Communication, Social Cognition, and Affect. Hillsdale: Lawrence Erlbaum; 1988.

[29] Wickens CD. Engineering Psychology and Human Performance. 2nd ed. New York: Harper Collins; 1992.

[30] Guznov S, Matthews G, Funke G, Dukes A. Use of the RoboFlag synthetic task environment to investigate workload and stress responses in UAV operation. Behav Resh Methods 2011; 43: 771-780.

[31] Valenzano A, Moscatelli F, Messina A, Monda V, Orsitto R, Zezza G, Fiorentino G, Salerno M, Triggiani AI, Viggiano A, Mollica MP, Carotenuto M, Monda M, Cibelli G, Messina G. Stress Profile in Remotely Piloted Aircraft Crewmembers During 2 h Operating Mission. Front Physiol 2018; 9: 461.

[32] Sterling BS, Perala CH. Workload, stress, and situation awareness of soldiers who are controlling unmanned vehicles in future urban operations Defence Technical Information Center. Army Research Laboratory 2007, Accession Number: ADA466480.

[33] Hancock PA, Mouloua M, Gilson R et al. Provocation: Is the UAV Control Ratio the Right Question? Ergonomics in Design 2007; 15: 7, 30.

[34] Lowe MS, Gire JT. In the mind of the predator: The possibility of psychological distress in the drone pilot community. Modern Psychological Studies 2012; 17: 2-7.

[35] Tang YWJ, Lao S. Research on the Collision Avoidance Algorithm for Fixed-Wing UAVs Based on Maneuver Coordination and Planned Trajectories Prediction. Appl Sci 2019; 9: 798.

[36] Bartone PT. The need for positive meaning in military operations. Military Psychology 2005; 17: 315-324.
[37] Nash WP, Litz BT. Moral injury: A mechanism for war-related psychological trauma in military family members. Clin Child Fam Psychol Rev 2013; 16: 365- 375.

[38] American Psychiatric Association, ed. Diagnostic and Statistical Manual of Mental Disorders. 5th ed. Arlington: American Psychiatric Association; 2013.

[39] Chappelle W, Goodman T, Reardon L, Prince L. Combat and operational risk factors for post-traumatic stress disorder symptom criteria among United States air force remotely piloted aircraft "Drone" warfighters. J Anxiety Disord 2019; 62: 86-93.

[40] Richter P, Hacker W. Belastung und Beanspruchung. Stress, Ermüdung und Burnout im Arbeitsleben. 4. Aufl. 2014, $211 \mathrm{~S}$. Asanger Verlag, ISBN 3-89334-324-9.

[41] Chappelle W, McDonald K, Thompson B, Swearengen J. Prevalence of High Emotional Distress and Symptoms of Post-Traumatic Stress Disorder in US Air Force Active Duty Remotely Piloted Aircraft Operators (2010 USAFSAM Survey Results). December 2012.

[42] Ouma JA, Chappelle WL, Salinas A. Facets of occupational burnout among US Air Force active duty and National Guard/reserve MQ-1 predator and MQ-9 reaper operators. 2011. Internet: www.dtic.mil/ dtic/tr/fulltext/u2/a548103.pdf.

[43] Otto JL, Webber BJ. Mental health diagnoses and counseling among pilots of remotely piloted aircraft in the United States Air Force. Medical Surveillance Monthly Report 2013/3, 20: 3-8.

[44] Maddi SR. Hardiness. Dordrecht Heidelberg New York London: Springer; 2012.

[45] Cornum R, Matthews MD, Seligman ME. Comprehensive soldier fitness: building resilience in a challenging institutional context. Am Psychol 2011; 66; 4-9.

[46] Werner A, Kreutzmann U, Ryvkin J, Glowka S, Schinkel C. Flugmedizin Tropenmedizin Reisemedizin, 2016; 23: 121-126. 